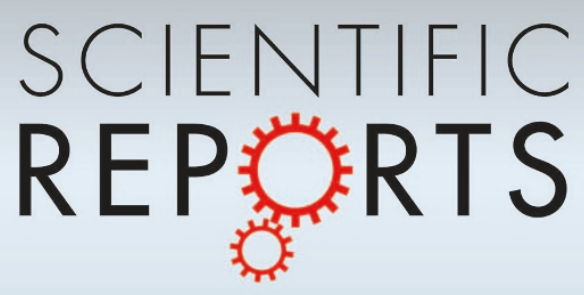

OPEN

SUBJECT AREAS:

ENVIRONMENTAL

BIOTECHNOLOGY

AGRICULTURAL GENETICS

Received

30 July 2014

Accepted

3 December 2014

Published

8 January 2015

Correspondence and requests for materials should be addressed to Y.L. (yunhe.li@hotmail. com); X.Y. (xinmingyin@hotmail. com) or Y.P. (yfpeng@ vip.qq.com)

\section{Consumption of Bt rice pollen containing CrylC or Cry2A does not pose a risk to Propylea japonica (Thunberg) (Coleoptera: Coccinellidae)}

\author{
Yunhe Li' ${ }^{1}$ Xiaojie Zhang ${ }^{1,2}$, Xiuping Chen' ${ }^{1}$ Jörg Romeis ${ }^{1,3}$, Xinming Yin ${ }^{2} \&$ Yufa Peng ${ }^{1}$
}

\begin{abstract}
'State Key Laboratory for Biology of Plant Diseases and Insect Pests, Institute of Plant Protection, Chinese Academy of Agricultural Sciences, Beijing, 100193, China, ${ }^{2}$ College of Life Science, Henan Agricultural University, Zhengzhou, 450002, China,

${ }^{3}$ Agroscope, Institute for Sustainability Sciences ISS, Zurich, 8046, Switzerland.
\end{abstract}

As a pollen feeder, Propylea japonica would be directly exposed to Cry proteins in Bacillus thuringiensis (Bt)-transgenic rice fields. The effect of Cry1C- or Cry2A-containing transgenic rice pollen on the fitness of $P$. japonica was assessed using two dietary-exposure experiments in the laboratory. In the first experiment, larval developmental time of $P$. japonica was significantly longer when fed pollen from $B t$ rice lines rather than control pollen but other life table parameters were not significantly affected. In the second experiment, $P$. japonica was not affected when fed a rapeseed pollen-based diet containing purified Cry1C or Cry2A at concentrations that were $>10$-times higher than in pollen, but $P$. japonica was affected when the diet contained E-64 as a positive control. In both experiments, the stability and bioactivity of the Cry proteins in the food sources and the uptake of the proteins by $P$. japonica were confirmed. The results show that $P$. japonica is not sensitive to Cry1C or Cry2A proteins; the effect observed in the first experiment was likely attributable to unknown differences in the nutritional composition of $B t$ rice pollen. Overall, the data indicate that the growing of Cry1C- or Cry $2 \mathrm{~A}$-transgenic rice should pose a negligible risk to $P$. japonica.

T $\mathrm{o}$ avoid potential risks to the environment associated with the planting of genetically engineered (GE) plants, any new GE plant must undergo a rigorous environmental risk assessment before it is approved for commercial cultivation. An important part of this assessment, especially in the case of insect-resistant GE plants ${ }^{1-4}$, is the evaluation of potential effects on valued non-target organisms (NTOs). The non-target risk assessment follows a tiered framework that typically starts with laboratory studies conducted under controlled, worst-case exposure conditions with the main objective of identifying the potential toxicity of the insecticidal proteins produced by the GE plants on surrogate test species $^{1,2,5}$.

The use of insect-resistant GE plants is an attractive approach for the control of insect pests. In China, many GE rice lines have been developed that produce Cry proteins derived from the soil bacterium Bacillus thuringiensis $(B t)$ and targeting lepidopteran pests, such as the Asiatic rice borer, Chilo suppressalis (Lepidoptera: Crambidae) ${ }^{6}$. Two recently developed $B t$ rice lines expressing $c r y 1 C$ or $c r y 2 A$ genes provided good resistance against stem borers and leaf folders throughout the rice growth period in laboratory and field experiments ${ }^{7-9}$. They therefore may have potential for commercial use in China. Data regarding their potential effects on valued NTOs, however, are limited. Recently, three laboratory studies indicated that larvae and adults of the green lacewing, Chrysoperla sinica (Neuroptera: Chrysopidae), are not sensitive to Cry1C and Cry2A proteins when provided in artificial diets or $B t$ rice pollen; the authors of these studies concluded that the planting of the $B t$ rice lines will pose a negligible risk to this species ${ }^{10-12}$. In addition, consumption of $B t$ rice pollen containing Cry1C or Cry2A protein was found to pose a low to negligible risk to larvae of the silkworm Bombyx mori (Lepidoptera: Bombyxidae) ${ }^{13}$.

Throughout East Asia, the ladybird beetle Propylea japonica (Thunberg) (Coleoptera: Coccinellidae) is a common and abundant predator in many cropping systems, including maize, cotton, rice, vegetables, and fruit trees $^{14-17}$. Both the larvae and adults consume aphids, thrips, spider mites, and eggs and young larvae of Lepidoptera ${ }^{18}$. In addition, they are known to use plant pollen, including rice pollen, as a complementary food source ${ }^{19-21}$. Therefore, this species may be exposed to plant-produced insecticidal proteins not only indirectly by consuming prey, but also directly by foraging pollen in Bt crops. This feeding ecology, together with the fact that 
Table 1 | Effect of consumption of pollen from CrylC- or Cry2A-expressing Bt rice (T1C-19 and T2A-1) or the corresponding nontransformed rice line (Minghui 63) on life table parameters of Propylea japonica. Number of replicates is indicated in parenthesis

\begin{tabular}{|c|c|c|c|c|c|c|}
\hline \multirow[b]{2}{*}{ Rice line } & \multirow{2}{*}{$\begin{array}{l}\text { Pupation } \\
\text { rate (\%) }\end{array}$} & \multirow{2}{*}{$\begin{array}{l}\text { Eclosion } \\
\text { rate }(\%)^{a}\end{array}$} & \multirow{2}{*}{$\begin{array}{c}\text { Days to } \\
\text { pupa }( \pm S E)^{b}\end{array}$} & \multicolumn{2}{|c|}{ Adult fresh weight $(\mathrm{mg} \pm \mathrm{SE})^{\mathrm{c}}$} & \multirow{2}{*}{$\begin{array}{c}\text { Total fecundity } \\
\text { per pair (eggs } \pm \mathrm{SE})^{c}\end{array}$} \\
\hline & & & & Female & Male & \\
\hline $\begin{array}{l}\text { Minghui } 63 \\
\text { T1C-19 (Cry1C) } \\
\text { T2A-1 (Cry2A) }\end{array}$ & $\begin{array}{l}97.3(75) \\
89.3(75) \\
90.7(75)\end{array}$ & $\begin{array}{l}90.7(75) \\
84.0(75) \\
81.3(75)\end{array}$ & $\begin{array}{l}7.99 \pm 0.11(73) \\
8.88 \pm 0.12(67)^{*} \\
8.62 \pm 0.10(68)^{*}\end{array}$ & $\begin{array}{l}6.97 \pm 0.13(30) \\
6.69 \pm 0.24(27) \\
6.53 \pm 0.18(26)\end{array}$ & $\begin{array}{l}5.96 \pm 0.14(37) \\
5.47 \pm 0.10(36) \\
5.50 \pm 0.15(35)\end{array}$ & $\begin{array}{l}177.2 \pm 14.64(30) \\
169.5 \pm 15.61(24) \\
137.6 \pm 10.40(25)\end{array}$ \\
\hline
\end{tabular}

Each $B t$ rice line was compared to the control. An asterisk denotes a significant difference between a $B t$ rice line and the control.

${ }^{2} \chi^{2}$ test with Bonferroni correction (adjusted $\alpha=0.025$ ).

bMann-Whitney U-test with Bonferroni correction (adjusted $\alpha=0.025$ ).

cDunnett test.

the species can be easily reared and is amenable for testing in the laboratory, makes $P$. japonica a suitable surrogate species for evaluating the potential effects of $B t$-transgenic plants on predacious Coccinellidae ${ }^{22,23}$. The species has been previously used to assess the non-target effects of $B t$-transgenic cotton ${ }^{18,24,25}$, maize $e^{26}$, and rice $^{14,27}$ in China.

In the present study, we investigated potential effects of feeding on $B t$ rice pollen containing Cry1C or Cry2A protein on P. japonica in the laboratory. In addition to this first experiment, we conducted a second experiment in which the beetles were directly exposed to purified Cry1C and Cry2A proteins mixed in rapeseed pollen-based diet at levels that were significantly higher than those present in $B t$ rice pollen. The second experiment, which used a dietary exposure system recently developed by our group ${ }^{21}$, was conducted to reduce the possibility that toxic effects were not missed in the laboratory. The second experiment also enabled us to draw general conclusions about the susceptibility of $P$. japonica to the two Cry proteins independent of the effects of the $B t$ rice varieties.

\section{Results}

Bt rice pollen experiment. Effects on life table parameters. When fed with rice pollen, over $80 \%$ of the $P$. japonica larvae developed to adults, and the percentage did not significantly differ between the $B t$ rice pollen treatments and the control pollen treatment $\left(\chi^{2}\right.$-test; both $P>0.05$ ) (Table 1). Similarly, the 15-day larval survival rates did not significantly differ between each $B t$ rice pollen treatment and the control (Cry1C: $\chi^{2}=2.30, P=0.13$; Cry2A: $\chi^{2}=2.27, P=0.13$ ) (Fig. 1). Larval development time, however, was significantly prolonged with $B t$ rice pollen (Mann-Whitney $U$-test; both $P<$ 0.001 ). Adult weight did not significantly differ between each of the Bt pollen treatments and the control pollen (Dunnett test; Cry1C: $P=0.47$ for females and $P=0.08$ for males; Cry2A: $P=$ 0.18 for females and $P=0.12$ for males). Fecundity also did not significantly differ between each of the $B t$ pollen treatments and the control pollen (Cry1C: $P=0.90$; Cry2A: $P=0.08$ ). Although differences in this first experiment were significant only for larval duration, pupation and eclosion rates, larval survival, adult fresh weights, and especially fecundity tended to be lower with $B t$ rice pollen than with control pollen (Table 1 and Fig. 1).

Uptake of Cry proteins by P. japonica. At the end of the Bt rice pollen experiment (30 days after adult emergence), ELISA measurements showed that all $P$. japonica adults that had been fed $B t$ rice pollen contained Cry protein. The mean concentrations $( \pm \mathrm{SE})$ of CrylC and Cry2A in P. japonica adults were $0.16 \pm 0.007$ and $1.05 \pm$ $0.40 \mu \mathrm{g} / \mathrm{g} \mathrm{DW}$, respectively. No Cry protein was detected in adults fed control pollen.

Stability and bioactivity of Cry proteins in rice pollen. According to ELISA, the original concentrations (mean $\pm \mathrm{SE}$ ) of CrylC and Cry2A were $2.25 \pm 0.33 \mu \mathrm{g} / \mathrm{g}$ and $37.85 \pm 3.74 \mu \mathrm{g} / \mathrm{g}$ DW in T1C19 and T2A-1 rice pollen, respectively. After a 2-d feeding exposure in the environmental chamber, Bt protein contents in the exposed pollen were not significantly different from those in the fresh pollen (Cry1C: $t=1.87, d f=4, P=0.14$; Cry2A: $t=0.48, d f=4, P=0.66$ ). No $B t$ protein was detected in samples of control rice pollen that were tested in parallel.

The sensitive-insect bioassay indicated that the mean weight of $C$. suppressalis larvae was significantly smaller when fed for 7 days on an artificial diet containing extract from the two $B t$ rice pollens rather than extract from control rice pollen $(P<0.001)$ (Fig. 2). Pair-wise comparisons revealed no statistical differences between the weights of C. suppressalis larvae fed extract from each $B t$ pollen that had been either freshly prepared or exposed to $P$. japonica larvae for 2 days $(P$ $>0.05)$ (Fig. 2).

Purified Cry protein experiment. Effects on life table parameters. As noted, all of the life table parameters measured in the first experiment tended to be adversely affected by $B t$ rice pollen treatments but the effect was statistically significant only for duration of the larval stage. Although these results suggest that $B t$ rice pollen might cause some toxic effects to $P$. japonica larvae, they could also be explained by other unknown differences between $B t$ rice pollen and control rice pollen. To further examine the effects of the Cry proteins on $P$. japonica larvae, and to do so without variation in the pollen, we used a diet containing rapeseed pollen augmented or not augmented with high concentrations of the Cry proteins; for CrylC the concentration used was 89-times that measured in T1C-19 pollen, for Cry2A the concentration used was 13-times that measured in T2A-1 pollen. The control used the same rapeseed pollen but without Cry protein.

Pair-wise comparisons revealed that the treatments containing Cry1C or Cry2A protein did not differ significantly from the

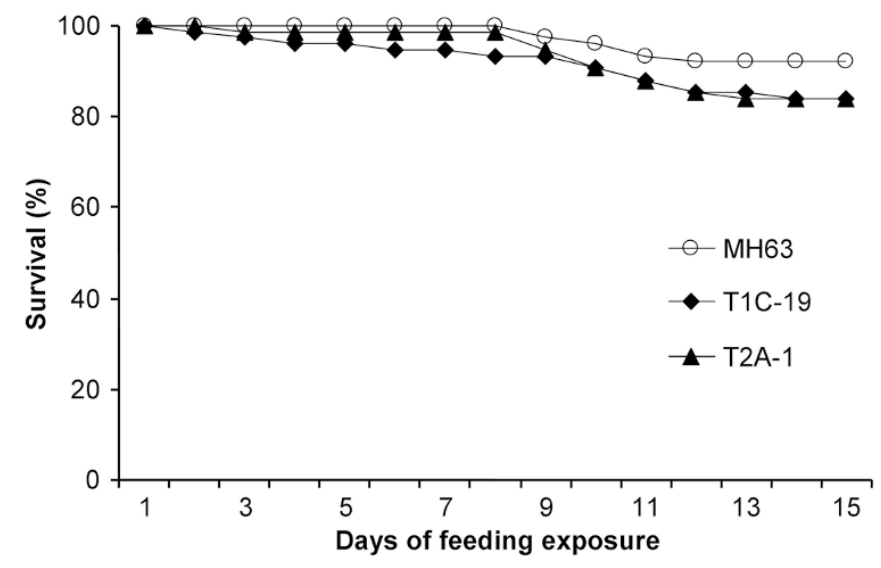

Figure 1 Survival of Propylea japonica larvae fed pollen from $B t$ rice (T1C-19 and T2A-1) or the corresponding non-transformed rice line (Minghui 63, MH63). Larvae were fed a combination of rice pollen and soybean aphids $(n=75)$. 


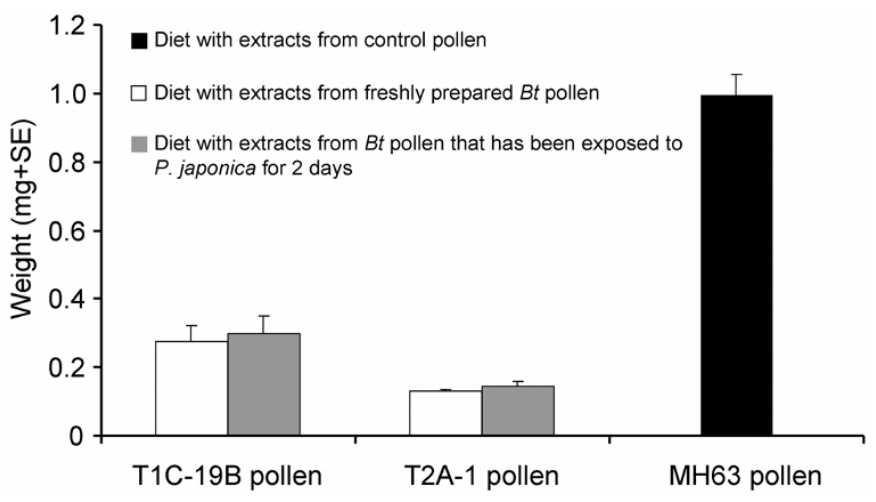

Figure 2 | Sensitive-insect bioassay with Cry protein extracted from pollen of $B t$ rice (T1C-19 and T2A-1) or the corresponding nontransformed rice line (Minghui 63, MH63). Weight (mean + SE, FW) of Chilo suppressalis larvae fed on artificial diets containing extracts from Minghui 63 rice pollen (control) or Bt pollen containing Cry1C or Cry2A that had been freshly prepared or that had been exposed to Propylea japonica larvae for $2 \mathrm{~d}(\mathrm{n}=30)$.

untreated (negative) control for pupation rate $\left(\chi^{2}\right.$-test; both $P>$ 0.10 ), eclosion rate (both $P>0.07$ ), and larval development time $(U=1374.0, P=0.08$ for Cry1C and $U=1440, P=0.28$ for Cry2A) (Table 2). Similarly, no significant difference was found between each of the Cry proteins and the negative control treatment for female and male FW (Dunnett's test; all $P>0.30$ ). Although total fecundity was reduced by more than $20 \%$ in the two Cry protein treatments relative to the control, the difference was not significant $(P=0.15$ for CrylC and $P=0.10$ for Cry2A). In contrast, $P$. japonica had significantly decreased pupation $\left(\chi^{2}=9.25, P=0.002\right)$ and eclosion rates $\left(\chi^{2}=\right.$ 23.64, $P<0.001)$ and a significantly prolonged larval developmental time $(U=6.0, P<0.001)$ when fed E-64 (Table 2). Likewise, the mean weight of the emerging adults was significantly reduced by $\mathrm{E}$ $64(P<0.01$ for both sexes) as was the total fecundity $(P<0.001)$. The survival rates were not significantly affected when $P$. japonica larvae were fed a rapeseed pollen-based diet containing Cry1C or Cry2A rather than a diet containing pure rapeseed pollen $(P>0.40)$, while survival was significantly lower in the E-64 treatment than in the control treatment $\left(\chi^{2}=11.1, P=0.001\right)$ (Fig. 3).

Uptake of Cry proteins by P. japonica. At the end of the second experiment (20 days after adult emergence), the mean ( \pm SE) Cry protein concentrations in adults were $2.21 \pm 0.37 \mu \mathrm{g} / \mathrm{g} \mathrm{DW}$ for Cry1C and $6.83 \pm 1.37 \mu \mathrm{g} / \mathrm{g}$ DW for Cry2A. No Cry protein was detected in adults that were fed a pure rapeseed pollen-based diet.

Stability and bioactivity of Cry proteins in rapeseed pollen. According to ELISA measurements, the original concentrations of Cry1C and Cry2A in the rapeseed pollen diet were $188.80 \pm 8.55 \mu \mathrm{g} / \mathrm{g}$ and

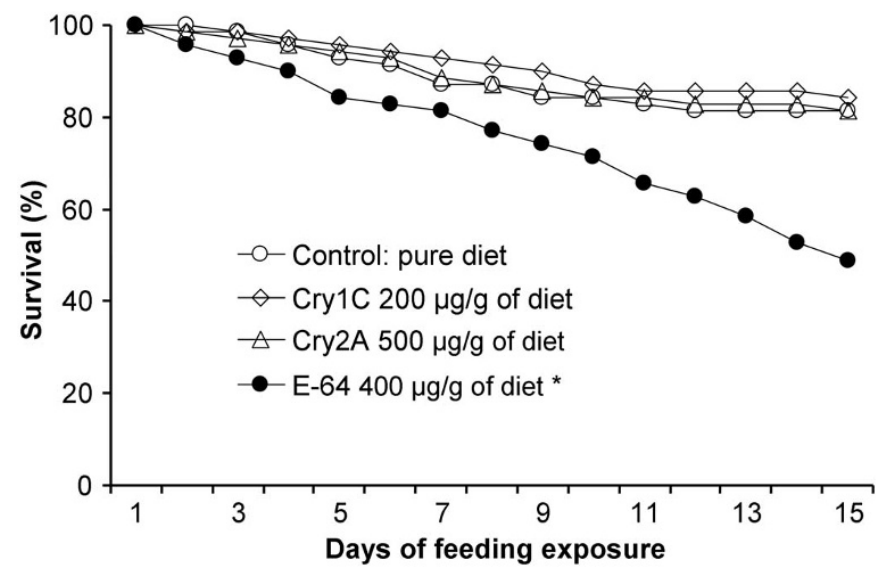

Figure 3 Survival of Propylea japonica larvae when fed rapeseed pollen containing Cry1C protein, Cry2A protein, or E-64. Larvae were fed a combination of rapeseed pollen, augmented or not with the insecticidal proteins, and soybean aphids. An asterisk denotes a significant difference between an insecticidal protein and the control $(\mathrm{n}=70)$.

$337.98 \pm 16.5 \mu \mathrm{g} / \mathrm{g} \mathrm{DW}$, respectively. After the 2-day feeding exposure in the environmental chamber, the Cry protein concentrations in the pollen were not significantly different from those in freshly prepared pollen diet (Cry1C: $132.2 \pm 20.5 \mu \mathrm{g} / \mathrm{g}, t=2.54, d f=2, P=$ 0.13; Cry2A: $318.9 \pm 8.6 \mu \mathrm{g} / \mathrm{g}, t=1.02, d f=4, P=0.36$ ).

The sensitive-insect bioassay showed that the mean weight of $C$. suppressalis larvae was significantly smaller when the artificial diet had been treated with Cry protein (all $P<0.05$ ) (Fig. 4). No statistical difference was detected between the weights of $C$. suppressalis larvae when fed a Cry protein-treated artificial diet that had been freshly prepared or that had been exposed to P. japonica for 2 days (Fig. 4).

\section{Discussion}

Laboratory studies are useful for determining whether Bt-transgenic plants pose a risk to non-target species ${ }^{2,28}$. Such studies allow experimenters to expose test organisms to Cry proteins under "worst-case exposure" conditions, i.e., at much higher levels and/or for significantly longer durations than occur in the field. Consequently, conclusions of "no adverse effects" can be made with high certainty

The results of our first experiment indicated that consumption of Cry1C- or Cy2A-containing transgenic rice pollen by $P$. japonica did not significantly reduce survival, pupation rate, eclosion rate, adult weight, or fecundity. There was a tendency, however, for all of these life table parameters to be lower with Cry1C- or Cy2A-containing transgenic rice pollen than with control pollen. Moreover, the developmental time (days from neonate to pupa) was significantly prolonged when P. japonica larvae were fed either Cry1C- or Cry2Acontaining rice pollen rather than control pollen. While these effects

Table 2 | Impact of purified Cry1C, Cry2A, and E-64 provided in a rapseed pollen-based diet on life table parameters of Propylea japonica. Number of replicates is indicated in parentheses

\begin{tabular}{|c|c|c|c|c|c|c|}
\hline \multirow[b]{2}{*}{ Treatment } & \multirow{2}{*}{$\begin{array}{l}\text { Pupation } \\
\text { rate }(\%)^{a}\end{array}$} & \multirow{2}{*}{$\begin{array}{l}\text { Eclosion } \\
\text { rate }(\%)^{a}\end{array}$} & \multirow{2}{*}{$\begin{array}{l}\text { Days to pupa } \\
\qquad(d \pm S E)^{b}\end{array}$} & \multicolumn{2}{|c|}{ Adult fresh weight $(\mathrm{mg} \pm \mathrm{SE})^{c}$} & \multirow{2}{*}{$\begin{array}{c}\text { Total fecundity per pair } \\
\text { (eggs } \pm \mathrm{SE})^{c}\end{array}$} \\
\hline & & & & Female & Male & \\
\hline $\begin{array}{l}\text { Control: pure diet } \\
\text { CrylC } 200 \mu \mathrm{g} / \mathrm{g} \text { diet } \\
\text { Cry2A } 500 \mu \mathrm{g} / \mathrm{g} \text { diet } \\
\text { E-64 } 400 \mu \mathrm{g} / \mathrm{g} \text { diet }\end{array}$ & $\begin{array}{l}84.3(70) \\
84.3(70) \\
82.9(70) \\
61.4(70)^{*}\end{array}$ & $\begin{array}{l}81.4(70) \\
82.9(70) \\
81.4(70) \\
41.4(70)^{*}\end{array}$ & $\begin{array}{c}8.57 \pm 0.12(59) \\
8.34 \pm 0.09(59) \\
8.59 \pm 0.20(58) \\
12.36 \pm 0.14(43)^{*}\end{array}$ & $\begin{array}{l}7.10 \pm 0.25(21) \\
7.42 \pm 0.21(28) \\
7.51 \pm 0.17(35) \\
5.80 \pm 0.15(18)^{*}\end{array}$ & $\begin{array}{l}6.25 \pm 0.13(36) \\
5.98 \pm 0.16(24) \\
6.06 \pm 0.18(29) \\
5.21 \pm 0.18(10)^{*}\end{array}$ & $\begin{array}{r}103.9 \pm 9.87(19) \\
82.1 \pm 7.11(20) \\
80.1 \pm 8.31(22) \\
7.4 \pm 2.54(10) *\end{array}$ \\
\hline \multicolumn{7}{|c|}{$\begin{array}{l}\text { Each toxin treatment was compared to the control. An asterisk denotes a significant difference between a toxin treatment and the control. } \\
\text { ' } \alpha^{2} \text { test with Bonferroni correction (adjusted } \alpha=0.017 \text { ). } \\
\text { bMann-Whitney U-test with Bonferroni correction (adjusted } \alpha=0.017 \text { ). } \\
\text { 'Dunnett test. }\end{array}$} \\
\hline
\end{tabular}




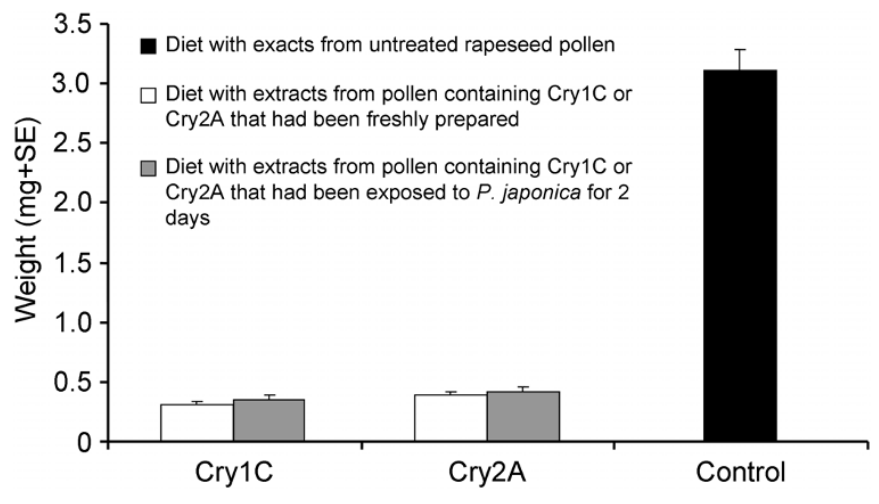

Figure $4 \mid$ Sensitive-insect bioassay with Cry proteins. Weight (mean + SE, FW) of Chilo suppressalis larvae fed on artificial diets containing exacts from untreated rapeseed pollen (control) or pollen containing CrylC or Cry2A that had been freshly prepared or had been exposed to Propylea japonica larvae for $2 \mathrm{~d}(\mathrm{n}=30)$.

might have been caused by toxicity resulting from consumption of Cry1C or Cry2A proteins, they might also have been caused by other unknown nutritional differences between the Bt-transgenic and control rice pollen, as has been reported for $B t$-transgenic and control maize pollen ${ }^{30,31}$.

Even though the developmental time was significantly prolonged when $P$. japonica larvae were fed pollen from $B t$ rice in experiment 1 , the effect was rather small, i.e., developmental time was increased by $8-11 \%$. This increase can be regarded as minor and is unlikely to affect the population dynamics of this species in the field considering that individuals will not exclusively develop on $B t$ rice pollen. For comparison higher tier field studies are triggered in the USA when a $50 \%$ increase in mortality is observed under laboratory conditions ${ }^{32}$; in the European Union a trigger of $20 \%$ is recommended ${ }^{33}$.

To eliminate potential differences in pollen unrelated to Cry protein content and to test the effects of even higher concentrations of Cry proteins, we conducted a second experiment in which rapeseed pollen was augmented (or not) with Cry proteins at concentrations that were more than 10-times greater than those in $B t$ rice pollen. That no adverse effects were detected in the second experiment suggests that the trends observed in the first experiment were caused by differences in pollen unrelated to Cry protein content. A similar phenomenon has been reported for the predatory mite Amblyseius (Neoseiulus) cucumeris (Mesostigmata: Phytoseiidae) when fed pollen from CrylAb-transgenic maize or the non-transformed control maize $^{30}$. Overall, the results of both experiments indicate that $P$. japonica is not sensitive to Cry $1 \mathrm{C}$ or Cry2A at the concentrations present in $B t$ rice pollen.

To draw clear and definitive conclusions from such dietary-exposure assays, researchers must confirm the stability and bioactivity of the test compounds in the food source and the uptake of the compounds by the test insects ${ }^{5,29,34}$. Our ELISA tests indicated that the Cry $1 \mathrm{C}$ and Cry $2 \mathrm{~A}$ concentrations in the $\mathrm{Bt}$ rice pollen in experiment 1 and in the rapeseed pollen in experiment 2 were stable. No degradation was observed during the 2-day feeding exposure to $P$. japonica. In addition, the bioactivity of the Cry proteins in the food sources was confirmed by bioassays with $C$. suppressalis larvae, which are susceptible to both Cry proteins. The uptake of Cry proteins by $P$. japonica was also confirmed. These results demonstrate that $P$. japonica was exposed to bioactive Cry proteins throughout both experiment at concentrations that were much higher than those expected to be encountered in $B t$ rice fields. In a previous study, for example, we showed that adult $P$. japonica that were collected in T2A-1 rice fields during anthesis contained less than $400 \mathrm{ng}$ of Cry2A per $\mathrm{g} \mathrm{DW}{ }^{20}$, while in the current study, Cry2A protein concentrations detected in adults of $P$. japonica exceeded $1 \mu \mathrm{g} / \mathrm{g}$ DW when fed T2A-1 rice pollen and exceeded $6 \mu \mathrm{g} / \mathrm{g}$ DW when fed rapeseed pollen containing purified Cry2A protein. In addition, the positive control compound E-64 that was included in experiment 2 reduced $P$. japonica survival, development, and fecundity. This result confirms that the test insect had ingested the test compounds and that the test system was able to detect adverse effects ${ }^{5,29}$.

Because of its ecological importance as a control agent of insect pests, $P$. japonica has been used as a representative non-target insect in several studies in which it has been fed purified Cry proteins, pollen from Bt-transgenic plants, or prey reared on Bt plants. Our previous study showed that the commercialized Cry proteins CrylAb, CrylAc, and Cry1F have no direct toxicity to this species ${ }^{21}$. Tritrophic studies also confirmed that the planting of GE maize and cotton producing Cry1A proteins is unlikely to have direct detrimental effects on P. japonica ${ }^{18,24,25,35}$. To our knowledge, only two published laboratory studies have assessed the potential non-target effects of $B t$ rice on $P$. japonica ${ }^{14,27}$. Neither study detected any adverse effects on $P$. japonica when the predator fed on Bt-pollen that contained Cry1 $\mathrm{Ab}^{14}$ or on Nilaparvata lugens (Homoptera: Delphacidae) that had been reared on CrylAb-transgenic rice plants ${ }^{27}$.

The current study is the first to assess the potential effects of Cry1C- and Cry2A-rice on predatory ladybirds in the laboratory, but the effects of Cry1C- and Cry2A-rice have been reported for three other non-target insects. Larvae and adults of the green lacewing, C. sinica, were not affected by feeding on Cry1C or Cry2A proteins or on Cry1C- or Cry2A-containing Bt rice pollen ${ }^{10-12,36}$. The planthopper, Laodelphax striatellus (Homoptera: Delphacidae), was not adversely affected when fed an artificial diet containing Cry2A at $300 \mu \mathrm{g} / \mathrm{g} \operatorname{diet}^{37}$. Larvae of the silkworm, B. mori, were fed Cry1C- or Cry2A rice pollen ${ }^{13}$. Although B. mori larvae were found to be sensitive to both Cry1C and Cry $2 \mathrm{~A}$ proteins, this was expected because $B$. mori is a lepidopteran, and the toxicity of CrylC and Cry $2 \mathrm{~A}$ proteins is lepidopteran specific. Nevertheless, taking natural exposure levels to $B t$ rice pollen into account, the authors concluded that consumption of $B t$ rice pollen will pose a low to negligible risk to $B$. mori $^{13}$.

In summary, the current study suggests that $P$. japonica is not sensitive to Cry1C and Cry $2 \mathrm{~A}$ proteins at concentrations that are more than 10-times higher than those detected in pollen from $\mathrm{Bt}$ rice. These results are consistent with those of most previous studies that have reported a lack of direct toxicity of the currently used Bt proteins (such as Cry1, Cry2, and Cry3) on ladybird beetles ${ }^{21,34,38,39}$. The increased developmental time for P. japonica larvae that directly fed on $B t$ rice pollen may be due to the altered nutritional composition of the $B t$ rice pollen caused by gene transformation or other unclear factors. We believe that this minor effect is unlikely to affect field populations of $P$. japonica, because the larvae will only deploy rice pollen as a supplementary food and thus consume much less rice pollen in the field than in our laboratory experiment. Therefore, we conclude that growing of Cry1C- and Cry2A-transgenic rice should pose a negligible risk to $P$. japonica.

\section{Methods}

Ethics statement. No specific permits were required for the described field studies. The rice fields where the $P$. japonica used in this study were originally collected were owned by the author's institute (Institute of Plant Protection, Chinese Academy of Agricultural Sciences, CAAS). These field studies did not involve endangered or protected species.

Insects. Specimens of $P$. japonica were collected in 2012 at the experimental field station of the Institute of Plant Protection, Chinese Academy of Agricultural Sciences (CAAS), near Langfang City, Hebei Province, China $\left(39.5^{\circ} \mathrm{N}, 116.7^{\circ} \mathrm{E}\right)$. A colony was subsequently maintained in the laboratory and augmented with field-collected insects in 2013. Insects were reared in the laboratory for at least two generations before being used in the current study. Both larvae and adults of $P$. japonica were reared on soybean seedlings infested with Aphis glycines (Homoptera: Aphididae). The aphids were replaced daily, ensuring ad libitum food. Newly hatched $(<12 \mathrm{~h}$ after emergence) $P$. japonica larvae were used for the experiments. 
A Bt-susceptible strain of Chilo suppressalis (Lepidoptera: Crambidae) was maintained in the laboratory on an artificial diet for over 60 generations ${ }^{40}$.

Rice pollen collection. Two transgenic rice varieties, T1C-19 and T2A-1, and their corresponding non-transformed near isoline, Minghui 63, were used for the experiments. T2A-1 plants express a modified cry $2 \mathrm{~A}$ gene, and T1C-19 plants express a modified $c r y 1 C$ gene; these genes encode for Cry proteins targeting lepidopteran rice pests. Minghui 63 is an elite indica restorer line for cytoplasmic male sterility in China. All rice seeds were kindly provided by Prof. Yongjun Lin (Huazhong Agricultural University, Wuhan)

The rice lines were simultaneously planted in three adjacent plots at the experimental field station of the Institute of Plant Protection, CAAS, near Langfang City $\left(39.5^{\circ} \mathrm{N}, 116.4^{\circ} \mathrm{E}\right)$. Each plot was approximately 0.02 ha, and plots were separated by a $1-\mathrm{m}$ ridge. The rice seeds were sown in a seeding bed on 8 April 2013, and the seedlings were transplanted into the experimental plots on 1 June, when the seedlings were at the four-leaf stage. The plants were cultivated according to the common local agricultural practices but without pesticide sprays.

During rice anthesis from 30 August to 15 September 2012, rice pollen was collected daily by shaking the rice tassels in a plastic bag. The collected pollen was airdried at room temperature for $48 \mathrm{~h}$ and subsequently passed through a screen with $0.125-\mathrm{mm}$ openings to remove anthers and contaminants. Pollen collected from each rice line was pooled and stored at $-80^{\circ} \mathrm{C}$ until used.

Insecticidal compounds and bee-collected pollen. Insecticidal compounds used in this study included the protease inhibitor E-64 [N-[N-(L-3-trans-carboxyoxirane-2carbony1)-L-leucyl]-agmatine)] and the Bt proteins Cry1C and Cry2A. E-64 was purchased from Sigma-Aldrich (St. Louis, MO, USA), and the Cry proteins were purchased from Envirotest-China (an agent for Envirologix Inc., Portland, Maine, USA; www.envirotest-china.com). The proteins were produced and purified at Case Western Reserve University (USA), where the protoxins from Bacillus thuringiensis had been expressed as single-gene products in Escherichia coli. The E. coli-expressed protoxin inclusion bodies then were dissolved and trypsinized. Subsequently they were isolated and purified by ion exchange HPLC followed by the desalting and lyophilization of the pure fractions. Purity was about $94-96 \%$.

Bioactivity of the batches of $B t$ proteins was demonstrated in our laboratory using neonate larvae of $C$. suppressalis that were fed for 7 days with an artificial diet containing a series of $B t$ protein concentrations. The $\mathrm{EC}_{50}$ (toxin concentration resulting in $50 \%$ weight reduction compared to the control) was estimated to be 18.1 for Cry1C and $1310.3 \mathrm{ng} / \mathrm{ml}$ for Cry $2 \mathrm{~A}^{11,12}$

Bee-collected rapeseed pollen used in the experiments was purchased from ChinaBee Science \& Technology Development Co., Ltd. (Beijing, China). The pollen granules were ground before being fed to P. japonica.

Experiments. Environmental conditions. All experiments were conducted in an environmental chamber at $26 \pm 1{ }^{\circ} \mathrm{C}, 75 \pm 5 \%$ relative humidity, and a $16: 8 \mathrm{~h}$ light: dark cycle.

Feeding system for $\mathrm{P}$. japonica. A pollen-based diet was previously developed for $P$. japonica in our laboratory. This diet, which uses bee-collected rapeseed pollen, supports normal survival and development of $P$. japonica (see Zhang et al., $2014^{21}$ for a detailed description). The $P$. japonica larvae were individually confined in Petri dishes $(6.0 \mathrm{~cm}$ diameter, $1.5 \mathrm{~cm}$ height). They were fed with pollen on the first day of each instar and then were provided with a mixture of pollen and soybean aphids (natural food) until development into the next instar. For adults, single pairs of $P$. japonica were confined in the same Petri dish and fed with pollen or with a combination of pollen and soybean aphids every other day. The pollen was directly sprinkled on the bottom of the Petri dishes, while the aphids were provided on $2-\mathrm{cm}$ segments of heavily infested soybean seedlings. Pollen was replaced every 2 days, while soybean aphids were replaced daily. In addition, an open $1.5-\mathrm{ml}$ centrifuge tube containing solidified $1 \%$ agar solution was added to each Petri dish as a water source. All of the food elements were provided ad libitum. For adults, several folded paper tapes $(0.6 \mathrm{~cm}$ width, $10 \mathrm{~cm}$ length) were provided as oviposition substrates. Preliminary experiments indicated that the rapeseed pollen could be replaced by rice pollen in this feeding system (data not shown). Bt rice pollen was used in the first experiment, and rapeseed pollen was used in the second experiment as described in the following sections.

Bt rice pollen experiment. With the feeding system described above, an experiment was conducted in which $P$. japonica was fed Bt or non-Bt (control) rice pollen. Seventy-five neonates of $P$. japonica were tested for each of three pollen treatments: (i) Minghui 63 rice pollen (control), (ii) T2A-1 rice pollen containing Cry2A, and (iii) T1C-19 containing Cry1C. Pupation rates, eclosion rates, and larval developmental time were recorded based on daily observation. When adults emerged, they were individually weighed using an electronic balance (CPA224S; Sartorius AG; readability $=0.1 \mathrm{mg}$, repeatability $< \pm 0.1 \mathrm{mg}$ ). Subsequently, the sex of the adults was determined, and randomly selected pairs were continuously fed with $B t$ or control rice pollen and soybean aphids as described above. A total of 24-30 pairs of adult $P$. japonica were tested for each treatment. The survival and total fecundity (number of eggs laid per female) were recorded based on daily observations. After 30 days, the first experiment was terminated. Three samples (thee adults per sample) were randomly selected to confirm the presence of Cry toxins in the insect bodies using double-antibody sandwich enzyme-linked immunosorbent assays (DAS-ELISA) as described below.

To determine the stability and bioactivity of the $B t$ proteins in the rice pollen during the first experiment, three pollen subsamples were taken from both $B t$ rice lines before and after being exposed to $P$. japonica for 2 days. The Cry protein concentrations in pollen samples were determined by ELISA, and the bioactivity was determined with a bioassay with Cry1C- and Cry2A-sensitive C. suppressalis larvae as described below.

Purified Cry protein experiment. The test system used for the second experiment was the same as described by Zhang et al. $(2014)^{21}$. Newly hatched larvae of $P$. japonica were individually assigned to one of four dietary treatments: (i) rapeseed pollen containing CrylC protein at $200 \mu \mathrm{g} / \mathrm{g}$ dry weight (DW) of pollen; (2) rapeseed pollen containing Cry $2 \mathrm{~A}$ protein at $500 \mu \mathrm{g} / \mathrm{g}$ DW of pollen; (3) rapeseed pollen containing E-64 protein at $400 \mu \mathrm{g} / \mathrm{g} \mathrm{DW}$ of pollen (positive control); and (4) rapeseed pollen (negative control). The Cry1C and Cry2A protein concentrations used here were thus 89 and 13-times higher than the concentrations in the respective $B t$ rice pollen (see Results). E-64 was selected as a positive control because it has been confirmed to be i) readily accepted and toxic to $P$. japonica at $400 \mu \mathrm{g} / \mathrm{g}$ DW; ii) a gut-active compound like the Cry proteins tested here; and iii) stable for the test duration ${ }^{21}$. With such properties, E-64 has been widely used as a positive control in multiple studies in which different Cry proteins were tested against coleopteran species ${ }^{5}$. Rapeseed pollen was used rather than rice pollen because it is commercially available and has been confirmed to be a highly nutritional food source for $P$. japonica (for details, see Zhang et al. $\left.2014^{21}\right)$. Soybean aphids were provided as a dietary supplement in each treatment as described above. Pollen-based diets were prepared before the beginning of the experiment and were stored at $-20^{\circ} \mathrm{C}$ until used. Diets were replaced every 2 days to avoid the degradation of the test compounds.

Experiment 2 was started with 70 neonates of $P$. japonica in each treatment. Larval development and mortality were recorded daily, and adults were weighed within $12 \mathrm{~h}$ of emergence. After the sex of the freshly emerged $P$. japonica adults was determined, randomly selected pairs were individually kept in the dishes as described above. Nineteen to 22 pairs of adults were tested in each of the control and $B t$ protein treatments, while only 10 pairs were tested in the E-64 treatment because of the high larval mortality in this treatment. The eggs laid by each female were counted daily. After 20 days, the second experiment was terminated. The living adults were kept at $-80^{\circ} \mathrm{C}$ before Cry toxins were quantified in their bodies using ELISA as described below.

To determine the stability and bioactivity of the $B t$ proteins in the rapeseed pollenbased diet during experiment 2 , three subsamples were taken from the pollen-based diet immediately after it was prepared and after it had been exposed to $P$. japonica for 2 days. The Cry protein concentrations in the diet samples were determined by ELISA, and bioactivity was determined by bioassay with Cry1C- and Cry $2 \mathrm{~A}$-sensitive C. suppressalis larvae as described below.

ELISA measurements. For both experiments, the concentrations of Cry1C and Cry2A in pollen and insects were measured by ELISA using Cry1C and Cry2A detection kits (QuantiPlate ${ }^{\mathrm{TM}}$ Kit, Catalog No. AP 007 and Catalog No. AP 005) from EnviroLogix Inc. (Portland, ME, USA).

Insects were washed in phosphate buffered saline Tween-20 (PBST) (provided with the kit) to remove $B t$ toxin or $B t$ rice pollen from their outer surface before the analysis. The samples of insects, $B t$ rice pollen, and rapeseed pollen were lyophilized and weighed. Subsequently, two tungsten carbide balls ( $3 \mathrm{~mm}$ diameter) were added to each tube, and the samples were ground for $4 \mathrm{~min}$ at $30 \mathrm{~Hz}$ in a mixer mill MM400 (Retsch, Haan, Germany) fitted with 24-tube adapters for microreaction tubes. For Cry protein extraction, samples were mixed with PBST at a ratio of $1: 10$ to $1: 100$ (mg sample: $\mu \mathrm{l}$ buffer) in 2-ml centrifuge tubes. After centrifugation at 13,000 rpm for 5 min and appropriate dilution of the supernatants, ELISA was performed according to the manufacturer's instructions. The optical density (OD) values were read with a microplate spectrophotometer (PowerWave XS2, BioTek, USA). The concentrations of Cry1C and Cry2A were calculated by calibrating the OD values to a range of concentrations of standard Cry1C and Cry $2 \mathrm{~A}$ samples.

Sensitive-insect bioassay. Larvae from a Bt-susceptible C. suppressalis strain were used to determine the bioactivity of the Cry $1 \mathrm{C}$ and Cry2A proteins in $B t$ rice pollen and the rapeseed pollen-based diet before and after exposure to $P$. japonica for 2 days. Supernatants from the extracts used for the ELISA analysis were appropriately diluted and thoroughly incorporated into the artificial diet for C. suppressalis larvae ${ }^{36}$, resulting in a final concentration of Cry1C and Cry2A of 100 and $3000 \mathrm{ng} / \mathrm{g} \mathrm{FW}$ of diet, respectively. Extracts of non- $B t$ rice pollen and control rapeseed pollen-based diet served as controls. The artificial diets were cut into slices and individually placed in Petri dishes ( $9 \mathrm{~cm}$ diameter, $1 \mathrm{~cm}$ height) together with a neonate larva of $C$. suppressalis. Subsequently, the Petri dishes were sealed with Parafilm and reinforced with surgical tape. After 7 days, the C. suppressalis were weighed. Thirty replicates were tested for each treatment.

Data analyses. Pair-wise statistical comparisons were made between Bt rice pollen and control rice pollen in the first experiment and between the Cry protein or E-64 treatments and the control in the second experiment. The effects of the dietary treatments on P. japonica were compared using the Kaplan-Meier procedure and Logrank test. Chi-square tests were used to compare pupation and eclosion rates, and Mann-Whitney $U$-tests were used to compare the larval developmental times because such data did not satisfy the assumptions for parametric analyses (normal distribution of residuals and homogeneity of error variances). Bonferroni corrections were 
applied for two and three pair-wise comparisons, resulting in an adjusted $\alpha$ of 0.025 and 0.017 , respectively. Data on adult weight and total fecundity were compared by Dunnett tests in both experiments.

In addition, Student's $t$-tests were conducted to compare Cry protein concentrations in fresh $B t$ rice pollen and in pollen that had been exposed to $P$. japonica larvae for 2 days. One-way ANOVA followed by Tukey HSD test was carried out to compare Cry protein concentrations in rapeseed pollen-based diet immediately after it was prepared and after it had been exposed to exposed to $P$. japonica larvae for 2 days, and for comparisons of the 7-day larval weight of C. suppressalis that were fed with artificial diets containing the extracts from the different pollen treatments.

All statistical analyses were conducted using the software package SPSS (version 13; SPSS, Inc., Chicago, IL).

1. Garcia-Alonso, M. et al. A tiered system for assessing the risk of genetically modified plants to non-target organisms. Environ. Biosafety Res. 5, 57-65 (2006).

2. Romeis, J.et al. Assessment of risk of insect-resistant transgenic crops to nontarget arthropods. Nat. Biotechnol. 26, 203-208 (2008)

3. Sanvido, O. et al. Evaluating environmental risks of genetically modified crops: ecological harm criteria for regulatory decision-making. Environ. Sci. Policy 15, 81-91 (2012).

4. Li, Y. H., Peng, Y. F., Hallerman, E. M. \& Wu, K. M. Safety management and commercial use of genetically modified crops in China. Plant Cell Rep. 33, 565-573 (2014)

5. Li, Y. H., Romeis, J., Wu, K. M. \& Peng, Y. F. Tier-1 assays for assessing the toxicity of insecticidal proteins produced by genetically engineered plants to non-target arthropods. J. Insect Sci. 21, 125-134 (2014)

6. Chen, M., Shelton, A. M. \& Ye, G. Y. Insect-resistant genetically modified rice in China: from research to commercialization. Annu. Rev. Entomol. 56, 81-101 (2011)

7. Tang, W. et al. Development of insect-resistant transgenic indica rice with a synthetic Cry1C* gene. Mol. Breed. 18, 1-10 (2006).

8. Chen, H., Zhang, G., Zhang, Q. \& Lin, Y. Effect of transgenic Bacillus thuringiensis rice lines on mortality and feeding behavior of rice stem borers (Lepidoptera: Crambidae). J. Econ. Entomol. 101, 182-189 (2008).

9. Wang, Y. N., Li, Y. H., Liu, Y. M., Han, L. Z. \& Peng, Y. F. Comparison of three transgenic Bt rice lines for insecticidal protein expression and resistance against a target pest, Chilo suppressalis (Lepidoptera: Crambidae). Insect Sci. Published on line, DOI 10.1111/1744-7917.12178 (2014).

10. Wang, Y. Y. et al. Consumption of Bt rice pollen expressing Cry2Aa does not cause adverse effects on adult Chrysoperla sinica Tjeder (Neuroptera: Chrysopidae). Biol. Control 61, 246-251 (2012).

11. Li, Y. H. et al. Bt rice expressing Cry2Aa does not cause direct detrimental effects on larvae of Chrysoperla sinica. Ecotoxicology. 22, 1413-1421 (2013).

12. Li, Y. H., Chen, X. P., Hu, L., Romeis, J. \& Peng, Y. F. Bt rice producing Cry1C protein does not have direct detrimental effects on the green lacewing Chrysoperla sinica (Tjeder). Environ. Toxicol. Chem. 33, 1391-1397 (2014).

13. Yang, Y. et al. Consumption of Bt rice pollen containing Cry1C or Cry2A protein poses a low to negligible risk to the silkworm Bombyx mori (Lepidoptera: Bombyxidae). PLoS ONE 9, e102302 (2014).

14. Bai, Y. Y., Jiang, M. X. \& Cheng, J. A. Effects of transgenic cry $1 A b$ rice pollen on fitness of Propylea japonica (Thunberg). J. Pest Sci. 78, 123-128 (2005).

15. Yang, J. H. Preliminary observations on the habits of Propylea japonica. Insect Knowl. 20, 215-217 (1983).

16. Zou, Y. D., Wang, H. F., Tao, Q. Z., Liu, D. K. \& Yu, W. Studies on predation of Propylaea japonica (Thunberg) larvae on Aphis gossypii Glover. Insect Knowl. 23, 219-222 (1986).

17. Zhou, K. J. \& Xiang, J. B. Observations on the efficacy of spiders and ladybirds against aphids in the seedling stage of cotton in the cotton fields. Nat. Enemy Insects 9, 17-20 (1987).

18. Zhang, S. Y., Li, D. M., Cui, J. \& Xie, B. Y. Effects of Bt-toxin Cry1Ac on Propylaea japonica Thunberg (Col., Coccinellidae) by feeding on Bt-treated Bt-resistant Helicoverpa armigera (Hübner) (Lep., Noctuidae) larvae. J. Appl. Entomol. 130, 206-212 (2006).

19. Li, K. S., Chen, X. D. \& Wang, H. Z. New discovery of feeding habitats of some ladybirds. Shanxi Forest. Sci. Technol. 2, 84-86 (1992).

20. Zhang, Q. L. et al. Exposure degree of important non-target arthropods to Cry2Aa in Bt rice field. Chin. J. Appl. Ecol. 24, 1647-1651 (2013).

21. Zhang, X. J. et al. Use of a pollen-based diet to expose the ladybird beetle Propylea japonica to insecticidal proteins. PLoS ONE 9, e85395 (2014).

22. Romeis, J. et al. Deriving criteria to select arthropod species for laboratory tests to assess the ecological risks from cultivating arthropod-resistant transgenic crops. Chemosphere 90, 901-909 (2013).

23. Carstens, K. et al. Surrogate species selection for assessing potential adverse environmental impacts of genetically engineered insect-resistant plants on nontarget organisms. GM Crops Food 5, 11-15 (2014)

24. Zhang, G. F., Wan, F. H., Guo, J. Y. \& Hou, M. L. Expression of Bt toxin in transgenic Bt cotton and its transmission through pests Helicoverpa armigera and Aphis gossypii to natural enemy Propylaea japonica in cotton plots. Acta Entomol. Sin. 47, 334-341 (2004).
25. Zhang, G. F., Wan, F. H., Lövei, G. L., Liu, W. X. \& Guo, J. Y. Transmission of $B t$ toxin to the predator Propylaea japonica (Coleoptera: Coccinellidae) through its aphid prey feeding on transgenic Bt cotton. Environ. Entomol. 35, 143-150 (2006)

26. Cui, L., Wang, Z., He, K. \& Bai, S. Effects of transgenic crylAh corn pollen on growth and development and adult mobility in Propylea japonica (Thunberg) (Coleoptera: Coccinellidae). Chin. J. Agric. Sci. 27, 564-568 (2011).

27. Bai, Y. Y., Jiang, M. X., Cheng, J. A. \& Wang, D. Effects of CrylAb toxin on Propylea japonica (Thunberg) (Coleoptera: Coccinellidae) through its prey, Nilaparvata lugens Stål (Homoptera: Delphacidae), feeding on transgenic Bt rice. Environ. Entomol. 35, 1130-1136 (2006).

28. Duan, J. J., Lundgren, J. G., Naranjo, S. \& Marvier, M. Extrapolating non-target risk of Bt crops from laboratory to field. Biol. Lett. 6, 74-77 (2010).

29. Romeis, J. et al. Recommendations for the design of laboratory studies on nontarget arthropods for risk assessment of genetically engineered plants. Transgenic Res. 20, 1-22 (2011).

30. Obrist, L. B., Klein, H., Dutton, A. \& Bigler, F. Assessing the effects of Bt maize on the predatory mite Neoseiulus cucumeris. Exp. Appl. Acarol. 38, 125-139 (2006).

31. Meissle, M., Zünd, J., Waldburger, M. \& Romeis, J. Development of Chrysoperla carnea (Stephens) (Neuroptera: Chrysopidae) on pollen from Bt-transgenic and conventional maize. Sci. Rep. 4, 5900 (2014).

32. Rose, R. I. White paper on tier-based testing for the effects of proteinaceous insecticidal plant-incorporated protectants on non-target invertebrates for regulatory risk assessment (USDA-APHIS and US Environmental Protection Agency, Washington, DC, USA, 2007) http://www.epa.gov/pesticides/ biopesticides/pips/non-target-arthropods.pdf (Date of access: 21/11/2014).

33. European Food Safety Authority (EFSA). Guidance on the environmental riskassessment of genetically modified plants. EFSA J. 8, 1879 (European Food Safety Authority, Parma, Italy, 2010) http://ec.europa.eu/food/food/ biotechnology/docs/20101112_era_guidance_era_guidance.pdf (Date of access: 21/11/2014).

34. Romeis, J., McLean, M. A. \& Shelton, A. M. When bad science makes good headlines: Bt maize and regulatory bans. Nat. Biotechnol. 31, 386-387 (2013).

35. Zhu, S. R. et al. Development and reproduction of Propylaea japonica (Coleoptera: Coccinellidae) raised on Aphis gossypii (Homoptera: Aphididae) fed transgenic cotton. Zool. Studies 45, 98-103 (2006).

36. Li, Y. H. et al. Use of an artificial diet system to study the toxicity of gut-active insecticidal compounds on larvae of the green lacewing Chrysoperla sinica. Biol. Control 69, 45-51 (2014).

37. Wang, Z. X. et al. Use of a dietary exposure system for screening of insecticidal compounds for their toxicity to the planthopper Laodelphax striatellus. Insect Sci. 21, 667-675 (2014)

38. Li, Y. H., Romeis, J., Wang, P., Peng, Y. F. \& Shelton, A. M. A comprehensive assessment of the effects of $\mathrm{Bt}$ cotton on Coleomegilla maculata demonstrates no detrimental effects by Cry1Ac and Cry2Ab. PLoS ONE 6, e22185 (2011).

39. Álvarez-Alfageme, F., Bigler, F. \& Romeis, J. Laboratory toxicity studies demonstrate no adverse effects of Cry1 Ab and Cry3Bb1 to larvae of Adalia bipunctata (Coleoptera: Coccinellidae): the importance of study design. Transgenic Res. 20, 467-479 (2011)

40. Han, L. Z., Li, S. B., Liu, P. L., Peng, Y. F. \& Hou, M. L. New artificial diet for continuous rearing of Chilo suppressalis (Lepidoptera: Crambidae). Ann. Entomol. Soc. Am. 105, 253-258 (2012).

\section{Acknowledgments}

We thank Prof. Yongjun Lin (Huazhong Agricultural University) for providing transgenic rice seeds. The study was supported by the National GMO New Variety Breeding Program of PRC (2014ZX08011-02B and 2014ZX08011-001).

\section{Author contributions}

Y.L. designed the study. X.Z. performed all the experiments. Y.L., X.Z., J.R. and X.Y. analyzed data and wrote the manuscript. X.C. and Y.P. provided experimental materials. All authors have read and approved the manuscript for publication.

\section{Additional information}

Competing financial interests: The authors declare no competing financial interests.

How to cite this article: $\mathrm{Li}$, Y. et al. Consumption of $B t$ rice pollen containing CrylC or Cry2A does not pose a risk to Propylea japonica Thunberg (Coleoptera: Coccinellidae). Sci. Rep. 5, 7679; DOI:10.1038/srep07679 (2015).

This work is licensed under a Creative Commons Attribution-NonCommercialNoDerivs 4.0 International License. The images or other third party material in this article are included in the article's Creative Commons license, unless indicated otherwise in the credit line; if the material is not included under the Creative Commons license, users will need to obtain permission from the license holder in order to reproduce the material. To view a copy of this license, visit http:// creativecommons.org/licenses/by-nc-nd/4.0/ 